Original Research Article

\title{
Assessment of prescribing pattern and cost analysis of topical steroids for skin disorders in dermatological outpatient department of a tertiary care hospital
}

\author{
Srinath S. ${ }^{1 *}$, Kavitha R. ${ }^{1}$, Dhanalakshmi K. ${ }^{2}$, Lyra P. Andrews ${ }^{2}$
}

${ }^{1}$ Department of Pharmacology,

${ }^{2}$ Department of Dermatology,

Karpaga Vinayaga Institute of

Medical Sciences,

Madurantagam Taluk,

Tamilnadu, India

Received: 29 April 2019

Accepted: 30 May 2019

\section{*Correspondence to:}

Dr. Srinath. S,

Email: srinathsamraj@

yahoo.com

Copyright: (C) the author(s), publisher and licensee Medip Academy. This is an openaccess article distributed under the terms of the Creative Commons Attribution NonCommercial License, which permits unrestricted noncommercial use, distribution, and reproduction in any medium, provided the original work is properly cited.

\begin{abstract}
Background: Topical steroid is most commonly prescribed in non-infective dermatological conditions. Periodical Prescription audit is mandatory for the effective management. Hence the present study is designed to assess the prescribing pattern and cost analysis of topical steroids for various skin disorders in the dermatology OPD of a teaching hospital.

Methods: This is a prospective observational study conducted in dermatology OPD of a teaching hospital from Jan-Mar 2019 in patients prescribed with topical steroids in all age groups after obtaining IEC approval. Data was analyzed for prescription pattern and cost analysis using descriptive statistics and expressed in percentage.

Results: A total of 90 prescriptions were analyzed among which males were $45 \%$ and females were $55 \%$, the common indications were eczema-27.7\%, atopic dermatitis-25.5\%, psoriasis-16.6\%, dermatoses-13.3\%, lichen planus-7.77\% etc. Topical steroids commonly prescribed were super potent (Clobetasol $34.4 \%$ and Halobetasol 22.2\%). Cream and ointment formulation were commonly used. Common adverse reactions were skin atrophy, hypopigmentation, acne. In prescribing pattern, specification of strength and quantity were lacking whereas instructions regarding area of application-44.4\%, route of administration-83.3\%, frequency and duration- $91 \%$ were noted. In cost analysis, comparison is made between similar potency and clinical outcome. Of which, Clobetasol $0.05 \%$ and Betamethasone $0.01 \%$ is found to be cost effective compared to Halobetasol $0.05 \%$ and Mometasone $0.1 \%$ respectively.

Conclusions: This study provides a limelight on prescribing pattern of topical steroids and emphasize periodic audit to rationalize the prescription with cost effectiveness.
\end{abstract}

Keywords: Cost analysis, Prescribing pattern, Topical steroids

\section{INTRODUCTION}

Dermatological conditions account for up to $2 \%$ of consultations in general practice worldwide. In India, the most prevalent dermatological conditions include dermatitis, urticaria, fungal skin infections, acne, alopecia, psoriasis, skin cancer and adverse drug reactions on the skin. ${ }^{1}$ Topical corticosteroids have revolutionized dermatologic therapeutics and are cornerstone of therapy in inflammatory skin disorders. Their therapeutic range varies from mild self-limiting conditions to life threatening problems. They reduce symptoms of inflammation, but do not address the underlying cause of disease. ${ }^{2}$

Inappropriate use of topical corticosteroids can alter the normal presentation of superficial bacterial and fungal 
infections or even predispose them. Topical corticosteroids have its own side effects like skin atrophy, acneiform dermatitis, telangiectasia, striae and so on. ${ }^{3}$ In order to counter these adverse effects and improve the efficacy, important factors to be considered while prescribing drugs are correct diagnosis, selection of the right drug, frequency of application, duration of treatment and consideration of adverse effects as they may have to be used for long term in many dermatological conditions.

Moreover since topical corticosteroids are prescribed for long term treatment which leads to economic burden to the patient. ${ }^{4}$ Periodical Prescription audit is mandatory for the effective management. Hence the present study is designed to assess the prescribing pattern and cost analysis of topical steroids for various skin disorders in the dermatology OPD of a teaching hospital.

\section{METHODS}

This is a prospective observational study conducted in the dermatology outpatient department of Karpaga Vinayaga Institute of Medical Sciences and Research Centre, Maduranthagam, Tamil nadu, India during the study period of 3 months from Jan 2019 to March 2019 with ethical clearance from Institutional Ethical Committee.

\section{Inclusion and Exclusion criteria}

After obtaining informed consent, 90 patients with various skin diseases prescribed only with topical corticosteroids from the outpatient department of dermatology were included in the study. Patients who were prescribed steroids in combination with other drugs, oral and IV steroids, previous history of steroid abuse, recent history of steroid application related complications, etc were excluded from the study

Demographic and prescription information like diagnosis, drug name, dosage data, strength, quantity, area of application, frequency of administration, duration were collected in a pre- designed proforma. Prescriptions with combination of topical steroids along with other drugs are not included in the study.

\section{Statistical analysis}

The data collected were analyzed using descriptive statistics and observed results were expressed in ratios and percentages.

\section{RESULTS}

A total of 90 prescriptions were analyzed among which males were $45 \%$ and females were $55 \%$ (Table 1), the common indications were eczema-27.7\%, atopic dermatitis-25.5\%, psoriasis-16.6\%, dermatoses-13.3\%, lichen planus-7.77\%, pityriasis rosea-4.44\%, irritant contact dermatitis-2.22\%, polymorphic light eruption$1.11 \%$, prurigo simplex-1.11\% (Table 2).
Table 1: Distribution of patients age and gender.

\begin{tabular}{|ll|}
\hline General information & $\mathbf{N}=90(\%)$ \\
\hline Gender & \\
\hline Male & $40(45 \%)$ \\
\hline Female & $50(55 \%)$ \\
\hline Age group & \\
\hline$<10$ years & $02(2 \%)$ \\
\hline$>10$ years & $88(98 \%)$ \\
\hline
\end{tabular}

Table 2: Disease pattern among study subjects receiving topical corticosteroids.

\begin{tabular}{|ll|}
\hline Skin diseases & $\mathbf{N}=\mathbf{9 0}(\%)$ \\
\hline Eczema & $25(27.7 \%)$ \\
\hline Atopic dermatitis & $23(25.5 \%)$ \\
\hline Psoriasis & $15(16.6 \%)$ \\
\hline Dermatoses & $12(13.3 \%)$ \\
\hline Lichen planus & $7(7.77 \%)$ \\
\hline Pityriasis rosea & $4(4.44 \%)$ \\
\hline Irritant contact dermatitis & $2(2.22 \%)$ \\
\hline Polymorphic light eruption & $1(1.11 \%)$ \\
\hline Prurigo simplex & $1(1.11 \%)$ \\
\hline
\end{tabular}

Topical steroids commonly prescribed were super potent among them, Clobetasol $34.4 \%$ and Halobetasol 22.2\% and among mid potent, Betamethasone $14.4 \%$ and Mometasone $17.7 \%$, hydrocortisone, desonide, fluocinolone were least prescribed (Table 3). Cream and ointment formulation was commonly used. Common adverse reactions were skin atrophy-5\%, hypopigmentation-3\%, acne- $2 \%$.

Table 3: Topical corticosteroids prescribed for study participants.

\begin{tabular}{|ll|}
\hline Topical corticosteroids & $\mathbf{N}=\mathbf{9 0}(\%)$ \\
\hline Clobetasol & $31(34.4 \%)$ \\
\hline Halobetasol & $20(22.2 \%)$ \\
\hline Mometasone & $16(17.7 \%)$ \\
\hline Betamethasone & $13(14.4 \%)$ \\
\hline Hydrocortisone & $5(5.5 \%)$ \\
\hline Desonide & $3(3.3 \%)$ \\
\hline Fluocinolone & $2(2.2 \%)$ \\
\hline
\end{tabular}

Table 4: Details of information included in prescriptions for topical corticosteroids.

\begin{tabular}{|ll|}
\hline Specified parameters in prescription & $\mathbf{N}=90(\%)$ \\
\hline Area of application & $40(44.4 \%)$ \\
\hline Route of administration & $75(83.3 \%)$ \\
\hline Frequency & $82(91 \%)$ \\
\hline Duration & $82(91 \%)$ \\
\hline Strength & $02(2.2 \%)$ \\
\hline Quantity & $00(0 \%)$ \\
\hline
\end{tabular}


In prescribing pattern, specification of strength and quantity were lacking whereas instructions regarding area of application- $44.4 \%$, route of administration- $83.3 \%$, frequency and duration- $91 \%$ were noted (Table 4). In cost analysis, comparison is made between similar potency and clinical outcome. Of which, Clobetasol $0.05 \%$ (Rs.68) and Betamethasone $0.01 \%$ (Rs.24.90) is found to be cost effective compared to Halobetasol $0.05 \%$ (Rs.163) and Mometasone $0.1 \%$ (Rs.132.50) respectively (Table 5).

Table 5: Cost analysis.

\begin{tabular}{|lllll|}
\hline Parameters & \multicolumn{3}{l|}{ Super potent } & \multicolumn{3}{l|}{ Mid potent } \\
\hline Drugs & Clobetasol vs Halobetasol & \multicolumn{3}{l|}{ Betamethasone vs Mometasone } \\
\hline Strength & $0.05 \%$ & $0.05 \%$ & $0.1 \%$ & $0.1 \%$ \\
\hline Amount & $15 \mathrm{gm}$ & $15 \mathrm{gm}$ & $20 \mathrm{gm}$ & $20 \mathrm{gm}$ \\
\hline Price & Rs. 68 & Rs. 163 & Rs. 24.90 & Rs. 132.50 \\
\hline CMM & Clobetasol & & Betamethasone & \\
\hline
\end{tabular}

(CMM- Cost Minimization Method)

\section{DISCUSSION}

Drug utilization studies provides a proper organized quality enhancement in assessing drug usage and prescribing pattern with current guidelines for the management of a certain disease. Prescriptions need to be audited occasionally to improve the therapeutic effectiveness, reduce the adverse effects, provide critical feedback to prescribers and scrutinize the execution of medical treatment standards. Topical corticosteroids are the most commonly prescribed medication in the dermatology outpatient department. ${ }^{5}$ Over usage of topical steroids leads to various adverse effects whereas its under usage leads to sub therapeutic effect. Moreover cost effectiveness of drugs with similar efficacy plays a vital role in continuing long- term treatment. ${ }^{4}$ Hence our study was designed to emphasize periodic audit to rationalize the prescription with cost effectiveness on topical corticosteroid

In present study, out of 90 prescriptions collected $45 \%$ were males and 55\% were females. Among all the population prescribed topical steroids, the most common indications were eczema $(27.7 \%)$ followed by Atopic dermatitis $(25.5 \%)$ which is comparable to the study done by Divyashanthi $\mathrm{CM}$ et al. ${ }^{6}$ The most common topical steroid prescribed was clobetasol $(34.4 \%)$ followed by halobetasol $(22.2 \%)$ and mometasone $(17.7 \%)$. These findings were comparable to the study done by Jena $\mathrm{M}$ et al. ${ }^{7}$ In contrast to it betamethasone was the most commonly prescribed medication according to the study done by Javsen $\mathrm{C}$ et al. ${ }^{8}$ The topical corticosteroids were commonly in the form of cream $44.5 \%$, ointment in $33.5 \%$ and as lotion in $22 \%$ of prescriptions.

Among the parameters in the prescription, only $2 \%$ of the prescriptions had strength of the drugs and regarding quantity required were not mentioned in any of the prescription which may lead to improper understanding by the patients and chances of dispensing medicine with strength of their choice which may lead to either low dose resulting in failure of therapy or adverse or toxic reaction due to over strength which is comparable to study done by Manju et al. ${ }^{9}$ Only in $44.4 \%$ of prescriptions details regarding specific area of application has been mentioned which might result in application over normal resulting in undue reactions or more systemic absorption as it varies in skin of different areas of skin. $83.3 \%$ of prescriptions carried information about route of administration. This is very important to avoid wrong usage.

Frequency and duration of administration were mentioned in $91 \%$ of prescriptions which is appreciable. It will be better to enter all the instructions clearly in the prescription and explain orally also in detail for proper and good adherence to the prescription which will bring out anticipated therapeutic outcome and satisfaction to the patients. Pharmacist should also be responsible in educating patients about correct application of topical corticosteroids, the frequency of application, and so on.

In cost analysis, clobetasol (34.4\%) in the super potent group and betamethasone (14.4\%) in the mid potent group were found to be cost effective in comparing halobetasol $(22.2 \%)$ and mometasone $(17.7 \%)$ respectively (Table 5). If the least-expensive topical steroid within each potency class had been substituted for the prescribed steroid, overall drug costs would have been lower, and out-ofpocket spending would have been much lower. ${ }^{10}$

\section{CONCLUSION}

Majority of skin diseases are chronic in nature and need lifelong treatment in which topical corticosteroids play a major role. By occasional monitoring, evaluating and analyzing the prescribing pattern of topical corticosteroids, we can contribute to the rationale and ethical use of this highly valuable drug with maximum effectiveness and least side effects. Hence, it is required for a prescriber to keep an organized account on prescription pattern and 
update it as and when needed especially in the case of topical corticosteroids.

Such periodic analysis of prescription regarding topical use of corticosteroids in dermatological conditions throughout the year is recommended to get an overall idea about the rational use of topical steroids so as to get the good therapeutic outcome which will also reduce the economic burden of the patients. Likewise, our study provides a limelight on prescribing pattern of topical steroids and emphasize periodic audit to rationalize the prescription with cost effectiveness.

\section{ACKNOWLEDGEMENTS}

Authors would like to thank my professor and our head of the department Dr. R. Kavitha for her immense effort in promoting me to do this study. I would also thank our college dermatology associate professor Dr. Dhanalakshmi and my wife Dr. K.R. Radheka for helping me in this study.

Funding: No funding sources

Conflict of interest: None declared

Ethical approval: The study was approved by the Institutional Ethics Committee

\section{REFERENCES}

1. Ritter JM, Lewis LD, Timothy GKM, Ferro A. Drugs and the skin. A textbook of clinical pharmacology and therapeutics, 5th ed. London, Hodder Arnold; 2008:411-419.

2. Werth VP. Systemic corticosteroids. In: Wolff K, Goldsmith LA, Katz SI, Gilchrest DA, Paller AS, Leffel DJ, eds.Fitzpatrick's Dermatology in General Medicine. $7^{\text {th }}$ ed. Newyork, MC Graw Hill; 2008:2147.
3. Fisher DA. Adverse effects of topical corticosteroid use. West J Med. 1995;162(2):123-6.

4. Skojec A, Foulke G, Kirby JS. Variation in the cost of generic topical corticosteroids. JAMA Dermatol. 2015;151(11):1255-6.

5. Das A, Panda S. Use of topical corticosteroids in dermatology: an evidence-based approach. Ind $\mathbf{J}$ Dermato. 2017;62(3):237-50.

6. Divyashanthi CM, Manivannan E. Prescribing analysis of corticosteroids among the dermatology in patients in a tertiary care teaching hospital, Karaikal, Puducherry. Int J Pharm Bio Sci. 2014;5:324-30.

7. Jena M, Panda M, Patro N, Mishra S. Pattern of utilization of corticosteroids in department of dermatology at a tertiary care teaching hospital. J Chem Pharmaceut Res. 2014;6(8):86-91.

8. Javsen C, Suman RK, Patil VG, Deshmukh YA. To study prescription pattern of corticosteroids in skin OPD in tertiary care teaching hospital. Asian J Pharmacol Toxicol. 2014;2(4):23-6.

9. Manju, Revathi, sakthi balan. Study of prescribing pattern of topical steroids in dermatology OPD, Karaikkal, Puducherry. Int $\mathrm{J}$ Pharmaco Res. 2018;8(1):01-5.

10. Song H, Adamson A, Mostaghimi A. Medicare Part D payments for topical steroids: rising costs and potential savings. JAMA Dermato. 2017;153(8):7559.

Cite this article as: Srinath $\mathrm{S}$, Kavitha R, Dhanalakshmi K, Andrews LP. Assessment of prescribing pattern and cost analysis of topical steroids for skin disorders in dermatological outpatient department of a tertiary care hospital. Int J Basic Clin Pharmacol 2019;8:1559-62. 